
demonstrator", SAE 2002 Transactions Journal of Materials and Manufacturing, pp196-203. ISBN 0-7680-1289-9.

\section{Minimum reasonable inventory and the bullwhip effect in an automotive enterprise; a "Foresight Vehicle" demonstrator}

\author{
M. M. Naim \& S. M. Disney \\ Logistics Systems Dynamics Group, Cardiff Business \\ School \\ G. N. Evans \\ Royal Bank of Scotland Group
}

\begin{abstract}
Demand amplification, or the bullwhip effect, has been identified as contributing to increased uncertainty in the supply chain and hence poor performance in terms of increased costs, protracted lead-times and poor customer service levels. This paper shows the application of a simulation based improvement activity focussing on the ordering decisions within a supply chain. An example of a preliminary business diagnostic and subsequent redesign in a four-tier automotive supply chain is presented including value-volume analysis, variability-volume analysis, part clustering and service level - stocking profiles. Specific improvements of up to 5 to 1 in stock holding are realized for continued customer service levels.
\end{abstract}

\section{INTRODUCTION}

"Bullwhip" is a phenomenon in supply chains that has been documented since the seminal work of Forrester [1] and Burbidge [2]. At that time the phenomenon was described as demand amplification [1] or the Law of Industrial Dynamics [2]. More recently Lee at al [3,4] has coined the term bullwhip.

Bullwhip is a symptom of poorly designed and managed supply chains. Hence, by measuring bullwhip it is possible to undertake a diagnostic, or health check, of a supply chain. It therefore is a suitable measure by which to judge the success, or otherwise, of a supply chain reengineering program. It is particularly pertinent to invest time and money up-front in a re-engineering process. The research approach described in this paper is akin will adopt the approach recently highlighted by Tomke (2001) for product design innovation but applied in the area of co-ordination system design innovation.

This paper aims to:
- highlight the overall research process adopted to diagnosing and solving a dynamic problem in an automotive supply chain

- describe the process of reducing bullwhip in an automotive supply chain with resulting reduction in inventory holding requirements while maintaining high customer service levels.

\section{BACKGROUND}

The simulation analysis described in this paper is just one element of a larger research program undertaken by the Logistics Systems Dynamics Group in partnership with LucasVarity (now TRW) and Computer Science Corporation under the auspices of a UK government funded Innovative Manufacturing Initiative (IMI) on Land Transport. The Supply Chain 2001+ project was instigated by LucasVarity in order to improve its supply chain capabilities and to achieve the "seamless supply chain vision". The future goal was to develop a route map (with associated methods, tools and techniques) that enable a current traditional supply chain to transform into the integrated, seamless supply chain.

The research is in line with IMl's general requirements and was developed with the IMI following the Road Vehicles Report [5] which identified the following research areas as fundamental building blocks necessary to implement many of the findings of business process analysis in supply chain engineering:

- better analysis tools, such as decision analysis

- simulation models of complete supply and distribution chains in order to run sensitivity analyses

- models that are able to cope not only with the movement of materials but also with the associated

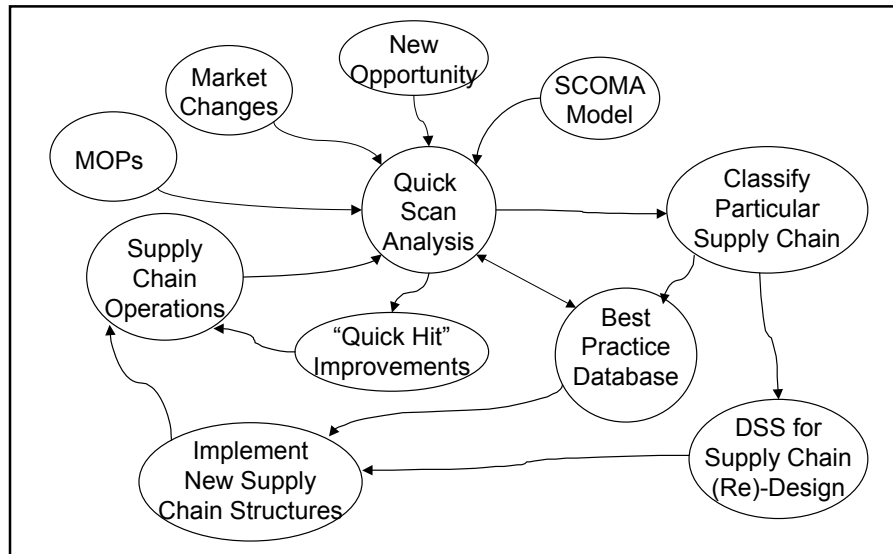

Figure 1: Overall Supply Chain 2001+ Process 

demonstrator", SAE 2002 Transactions Journal of Materials and Manufacturing, pp196-203. ISBN 0-7680-1289-9.

information

The original proposal also identified that generic research is required in the above three areas, as reinforced by the Technology Foresight Program [6] which highlights the need for UK industry in general to develop "business simulations (which) should include supply chain logistics".

The project developed a re-engineering methodology for supply chains. This includes a systems engineering and simulation based dynamic Decision Support System based on industry standard software. It allows the elimination of wasteful processes, the improvement of quality, cost and delivery to customers, and allows the development of leaner, agile and more customer responsive business practices.

\section{METHODOLOGY}

The overall supply chain engineering framework developed in the research program is summarized in Figure 1.

The process may be applied via project teams, or Task Forces, involving the collection of empirical data, model building and their validation within businesses. The process has to be in line with the requirements of the market place (i.e. to deliver total value to the consumer) and the opportunities that arise for a business. At the heart of the process is the Supply Chain Optimization Modelling Architecture (SCOMA) as shown in Figure 2.
SCOMA has enabled focus for the rest of the research process. Thus, the Quick Scan method has been developed to efficiently use resources to effectively understand and document the supply chain $[8,9]$. The Quick Scan highlights "hot" spots (and "beauty" spots) so as to make recommendations to businesses on potential "Quick Hit" (not quick fix) improvements and longer-term major opportunities to engineer new supply chain structures. As can be seen from the process model in Figure 1 (re)engineering the supply chain requires due consideration of supply chain type.

An important premise of the research is that no single solution (or paradigm) fits all supply chain types. Therefore, the ability to classify supply chains is an important pre-requisite to supply chain engineering. Once the Quick Scan has diagnosed the problems and we are able to determine the supply chain type we have analyzed then, with reference to a Best Practice database, we can determine appropriate solutions. Importantly the Best Practice database will not simply be a collection of numbers but will have vital cause and effect relationships so that causes are tackled and not simply their symptoms.

The assessment of supply chain engineering strategies is undertaken via a Decision Support System (DSS) that utilizes software modeling and simulation tools appropriate to the level of SCOMA being optimized. This paper highlights the application of system dynamics modeling and simulation in determining solutions for an inventory holding and customer service level problem at Level $2 b$ of SCOMA.

SCOMA allows the decomposition of highly complex supply networks into three levels so as to ensure ease of conceptualization while maintaining adequate scope. The scope includes width (flows of material, resources, cash and information), depth (organizational,

technological, financial and attitudinal issues) and breadth (work, business, supply chain and networks) [7]. At each level we are able to determine the right methods, tools and techniques to firstly understand and document the supply chain and then to simplify (including waste elimination) and optimize. It is important to ensure that we determine the right solutions to solve the appropriate problems.
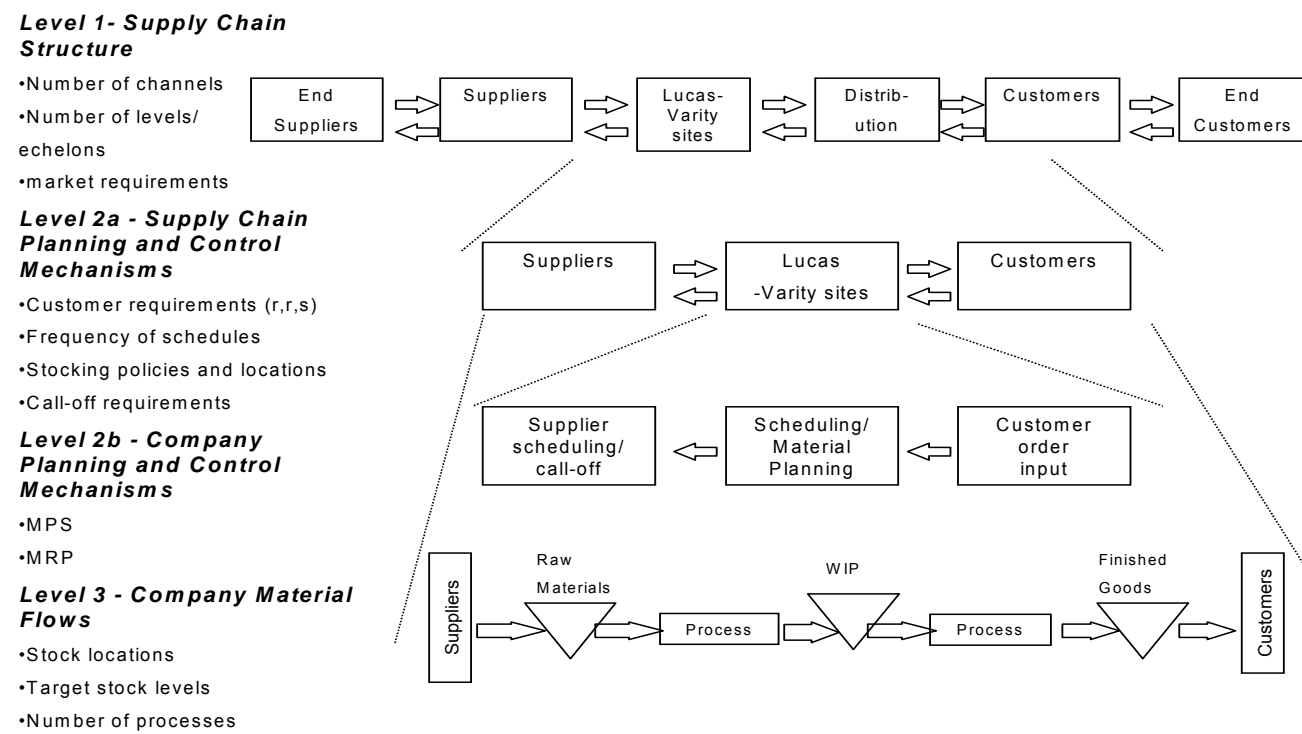

Figure 2: The SCOMA framework 


\section{THE CASE}

The company under study is a first tier system supplier to the vehicle manufacturers (including Nissan, Rover (now MG), Honda, Toyota, Jaguar) and the aftermarket sector. The research involved an analysis of one particular site over a period of six months during which one of the authors was seconded one of the site's change program task forces. During the period of analysis the site produced 324 finished goods parts numbers (out of a total range of 2329) accounting for a total volume of 3.16 million parts and a total value of $\$ 21.3$ million.

The research was instigated following the application of the Quick Scan diagnostic. Prior to wholesale implementation of re-engineering strategies there is a need to understand and document the characteristics, issues and problems associated with a particular supply chain. The fundamental approach to the research has been "find the right solution for the right problem" and NOT "one size fits all".

The Quick Scan was developed in order to understand and document a business' supply chain and make recommendations on the most appropriate solutions to their logistics problems in the short, medium and long terms. The specification from the industrial partners' perspective was to develop a method that maximized the depth of understanding while at the same time it

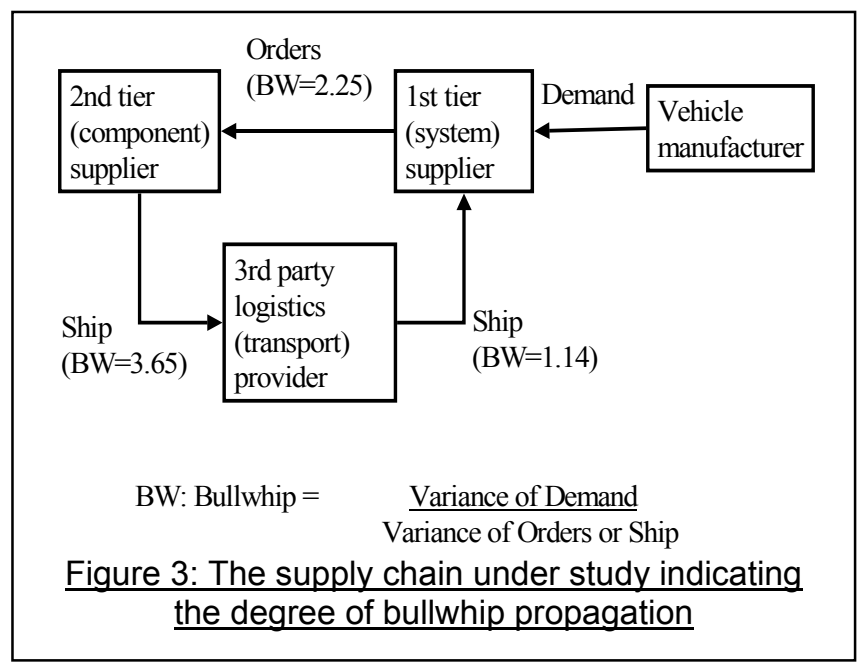

minimized the resources required to undertake the business diagnostic.

The actual Quick Scan on-site data collection is usually undertaken over a 2-3 day period but is supported by 910 days of detailed analysis, 1-2 days of preliminary buy-in presentations and 1-2 days of documentation and reporting findings. The data collection is triangulated to ensure rigor and accuracy. Opinions, empirical, archival and analytical methods of data collection are therefore synthesized. Well-established manufacturing systems engineering techniques (some recently marketed by the lean thinking doctrine in the form of value stream mapping tools) are utilized in the data collection.

The Quick Scan was undertaken of the first tier supplier's supply chain indicated in Figure 3. The boundaries of the analysis were the interface with the vehicle manufacturer, the first tier suppliers, a second tier supplier and a third party logistics provider (including transport and warehousing services).

The Quick Scan highlighted a number of improvement opportunities for both individual business units and the supply chain as a whole. Those of common supply chain interest included:

SYNCHRONISATION - The supply chain is inherently unsynchronized with the $1^{\text {st }}$ Tier Supplier operating on 6 working days and the $2^{\text {nd }}$ Tier Supplier on 5 working days. This is compounded with unsynchronized pallet quantities in the process which could be tackled via common batch sizes throughout the supply chain.

SUPPLY CHAIN COOPERATION - the $3^{\text {rd }}$ Party Logistics Provider has frequent supply chain reviews; yearly, $1 / 2$ yearly and quarterly. The $1^{\text {st }}$ Tier Supplier is not involved in these reviews thereby missing the 
opportunity to influence, and to learn from, the improvement exercises undertaken. An example is the elimination of non-value adding activities such as material decanting leading to varying delivery quantities and lead-times.

ORDER GENERATION - The order generation for raw material parts needs to be changed through the supply chain as the current system induces the bullwhip effect. This is highlighted in Figure 3 where the bullwhip for a specific product is indicated. Bullwhip is taken as the ratio of the variance of the vehicle manufacturer's demand to the variance in the signal of interest $[3,4]$. Thus, it can be seen in terms of ordering the $1^{\text {st }}$ Tier Supplier induces uncertainty (in terms of schedule fluctuations) on to the $2^{\text {nd }}$ Tier Supplier. This in turn generates uncertainties in shipments at each stage of the supply chain.

The latter issue is of particular interest in this paper. The bullwhip phenomenon and its impact on supplier performance, leading to a vicious circle of determinant to the total supply chain, is well documented in the literature $[10,11]$. Analysis of the $1^{\text {st }}$ Tier Supplier's internal process yielded a number of contributory factors leading to bullwhip in the supply chain, high stock levels, poor supplier delivery performance and low finished goods availability for the vehicle manufacturers.

A summary of the Quick Scan outputs at the $1^{\text {st }}$ Tier Supplier is shown as a cause and effect diagram in Figure 4. Highlighted in Italics are those variables contributing to the bullwhip effect and which ultimately lead to poor customer service levels. As can be seen, variation in vehicle manufacturers customer orders in themselves lead to production planning changes, lost assembly capacity and ultimately the inability to deliver product to the customers. This effect is reinforced by the feedback loop whereby production planning changes leads to order variations to the $2^{\text {nd }}$ Tier Supplier who, due to these uncertainties, has difficulty in satisfying requirements leading to poor raw

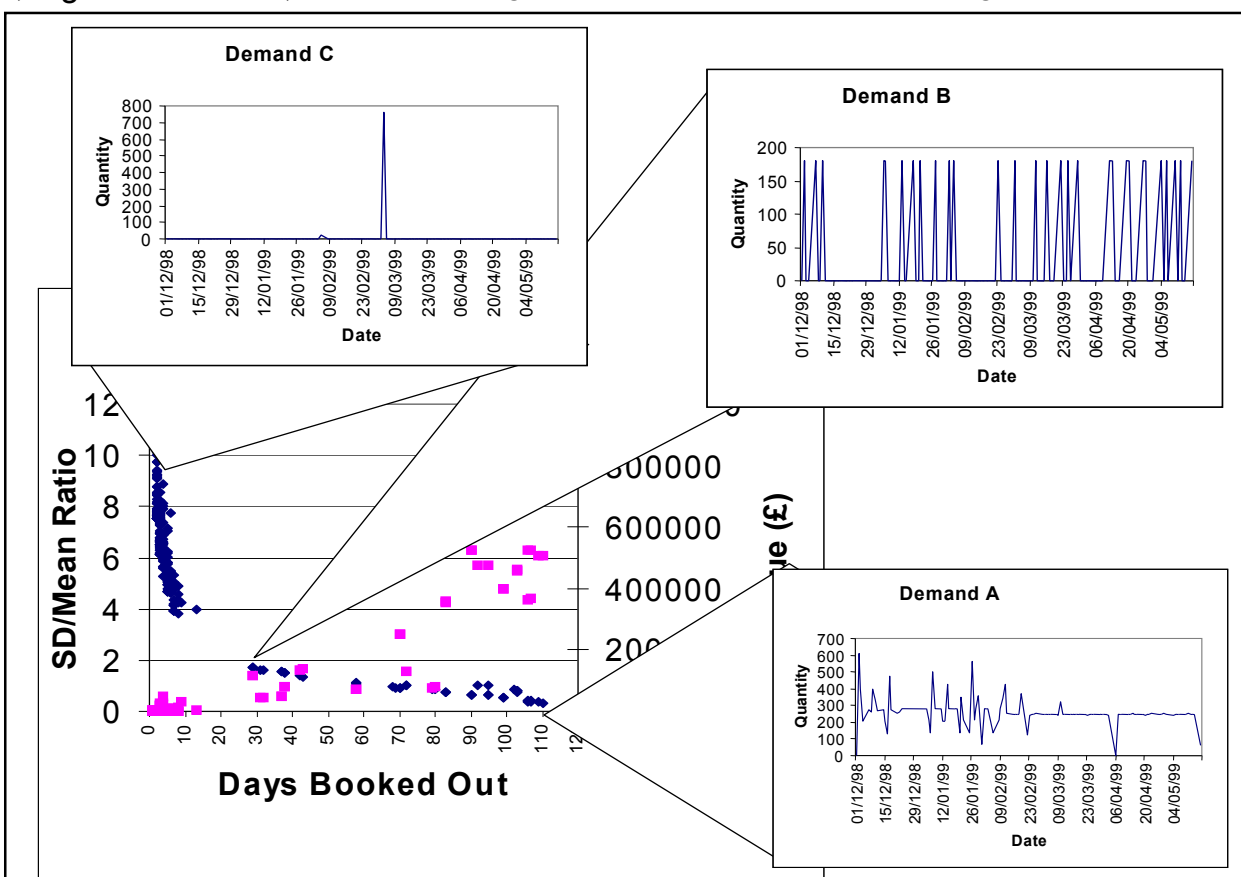

Figure 6: $A B C$ analysis of finished goods parts 
levels. The objectives of the research were;

- Obtain finished goods, raw material and bill of material data from the $1^{\text {st }}$ Tier Supplier's production planning and control system

- Formulate realistic minimum reasonable inventory level versus customer service level trade-off scenarios

- Build appropriate system dynamics models and simulate the scenarios

- Feedback results and make recommendations

438 raw material part numbers were analyzed out of a total of 1114 that were available in the $1^{\text {st }}$ Tier Supplier's production planning and control system. The choice of part numbers was based on those products that were "live" during the period of analysis. Time series and statistical analysis was undertaken on the data collected. Figure 5 gives an example of an analysis that yielded considerable insight into the dynamic properties of product usage.

The mean and standard deviation of each part is determined and related to the frequency of usage. The value of the product usage is also determined so as to ascertain the cost implications of stock holding.

Figure 6 shows a sample of related time series and categorizes them according to the runners-repeatersstrangers (or ABC analysis) profile [12]

The $A$ and $B$ product usage patterns are relatively predictable In total account for a low percentage of the total volume but are relatively high value in terms of total turnover. They also account for high stock holding value.

In contrast the $\mathrm{C}$ items are exceptions and hence far more unpredictable. They constitute a high percentage of the total volume from the plant but are relatively low value in comparison with $A$ and $B$ products in terms of turn over and stock holding value.

Two distinct clusters were therefore identified as indicated in Figure 7. A recommendation from the research was to distinguish between these two product clusters for production planning and control purposes. The $1^{\text {st }}$ Tier Supplier had already segregated the two clusters for operational purposes via dedicated

\section{Volume}

,345,599 Units (75.2\%)

Turn Over Value

$\$ 0.89$ million (4.2\%)

Ill Stock Cost Average

$\$ 0.67$ million

Volume

816,851 Units (25.8\%)

Turn Over Value

\$20.4 million $(95.8 \%)$

All Stock Cost Average $\$ 1.55$ million

Figure 7: Cluster analysis of finished goods parts

production and assembly lines but had aggregated them for the purposes of planning.

The $C$ category items should be treated on a project basis. It is logical to order in C products and ship them as discrete orders. This requires ordering from suppliers with a known lead-time. The production planning and control does not currently have supplier lead-times but simply relies on safety stock target figures for ordering purposes. The safety stock calculations are static and are not dynamically updated and should be dependent on the usage time series characteristics as well as leadtime estimates.

$A$ and B category items were the subject of simulation analysis. The task force champion, who happened to be the Manufacturing Director of the site, suggested that stock holding could be reduced without any detriment to product availability. His gut feel was that stock levels could be reduced from a current average level of 5 days to 3 days.

The simulation was undertaken utilizing proprietary spreadsheet software and implemented via difference equations. The model incorporated an ordering rule based on smoothed values of usage and a percentage of stock error replenishment [13,14]. Actual usage time series drove the simulation and stock levels, customer service levels and bullwhip were measured as outputs.

Figure 8 shows a radar plot of days worth of stock holding costs for the different products simulated. This indicates that for the majority of products careful design of the ordering rule (by determining the degree of smoothing and the percentage of inventory error 

demonstrator", SAE 2002 Transactions Journal of Materials and Manufacturing, pp196-203. ISBN 0-7680-1289-9.

replenishment) can have a major impact on reducing sock holding costs for a given availability requirement. For certain products, the impact is minimal. Subsequent investigations revealed that these were Category $A$ items where there was almost level scheduling by Japanese or Japanese transplant vehicle manufacturers.

Figure 9 shows the comparison between the MD's "gut feel" 3-day target with the simulation analysis' profiled and average stock holding requirements. As can be seen the MD's suggested target is not far from the analysis target of 2.5 days. But it is worth noting the dangers of a blanket target figure. In some cases 2.5 days will lead to excess stock while in other cases such a target would in insufficient to meet availability requirements. A clear lesson is that that an ordering strategy has to be developed for particular categories while each product has to have its ordering parameters defined.

The design of the ordering rules also impact on the bullwhip induced and propagated along the supply chain. Trade-off considerations are required at this stage between the degree of volatility present in the order propagated to suppliers and the volatility absorbed by stock.

In the $\mathrm{C}$ category items the orders received from the vehicle manufacturers are passed on to the $2^{\text {nd }}$ Tier Supplier. Thus, based on the nomenclature of Figure 3, Orders BW = 1.0. For category $A$ and $B$ items it is also possible to pass on orders (in the case of those customers level scheduling) or alternatively an attempt is made at damping down the variation received from the vehicle manufacturers. In the latter case Orders bullwhip can be as low as 0.44 .

Another consideration is the impact of parameter changes in the simulation models developed. That is, we can test the impact of real world changes on the design strategies. A scenario developed by the task force was to ascertain the impact of lead-time changes on stock holding and product availability. The $1^{\text {st }}$ Tier Supplier has been undertaking a lean change program

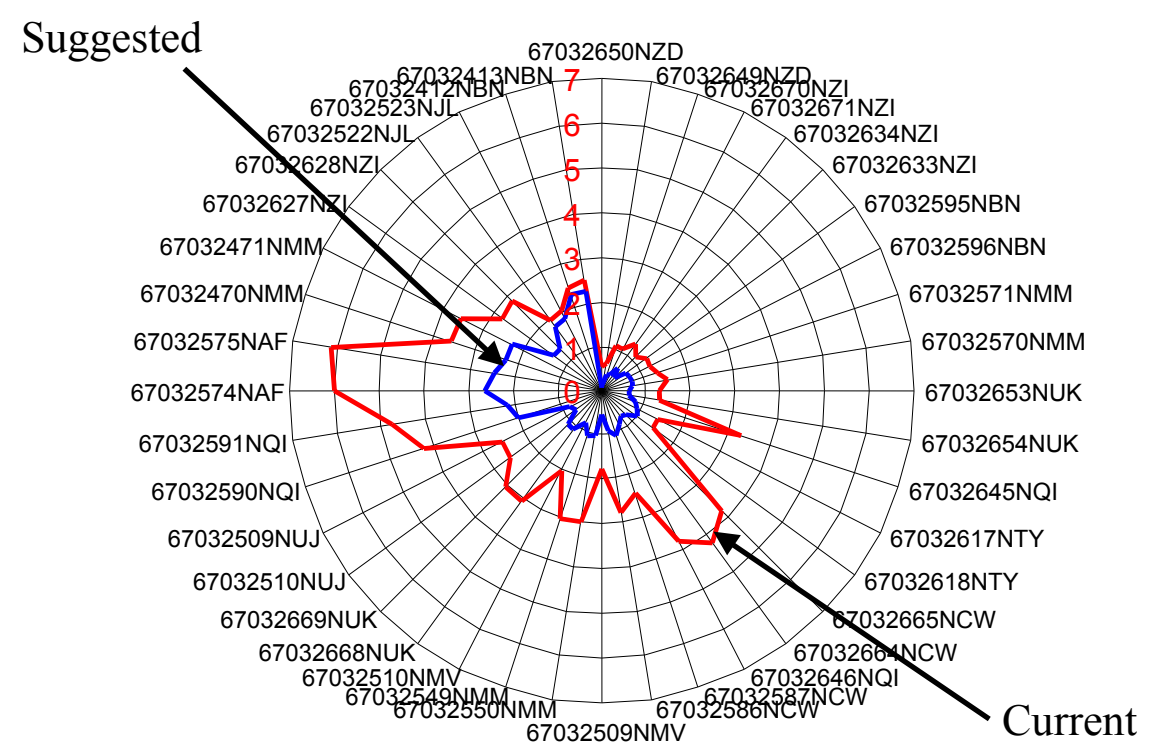

Figure 8: Radar plot of current and suggested stock holding (in days)

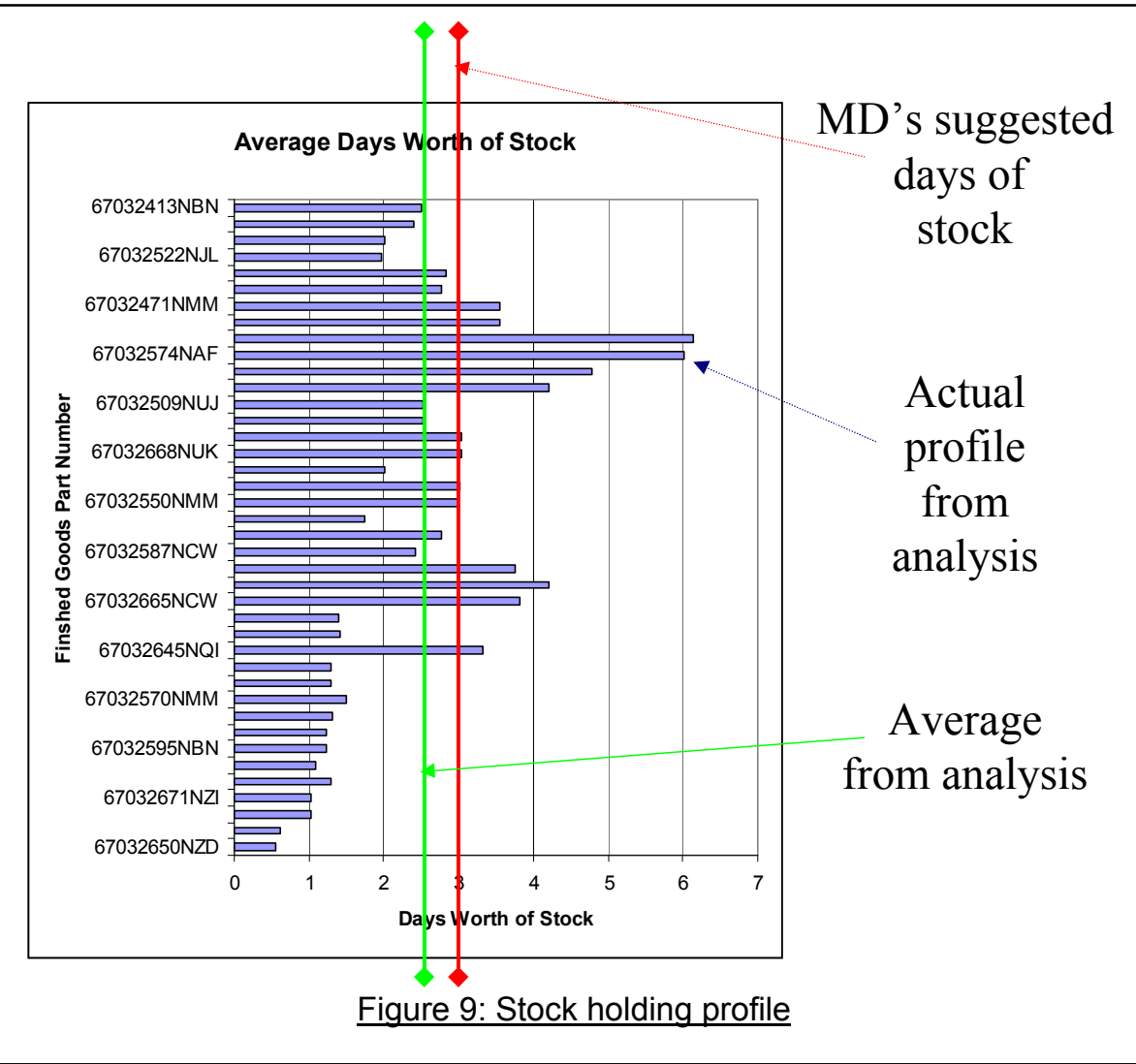

over a number of years internally and with its supply base.

Figure 10 shows a stock versus customer service level (CSL) availability profile for a particular finished goods product. Also shown on the figure is a dotted band indicating the current range of both the level stock 

demonstrator", SAE 2002 Transactions Journal of Materials and Manufacturing, pp196-203. ISBN 0-7680-1289-9.

keeping units (SKU) and the level of customer service level availability.

The profiles give the trade-off between stock holding and CSL availability. Thus, for a CSL availability of $96 \%$ entails the holding of approximately $\$ 225$ thousand worth of stock. It can also be seen from Figure 10 that a $50 \%$ reduction in lead-time leads to only a $14 \%$ reduction in SKU costs for a given CSL. This indicates that effort should primarily be focused on defining appropriate ordering protocols with customers and enhancing the dynamic characteristics of the production control system. The need for further "leaning" of the supply and production process is a secondary activity.

\section{DISCUSSION}

The above case is a demonstrator of the application of simulation modeling at Level 2 of the SCOMA architecture. But as well as being a practical example of how dynamic modeling may aid in decision making of stock, production and ordering planing and control the case also reinforces the "uncertainty circle model" that has been developed as part of the Supply Chain 2001+ and associated research.

Uncertainty leads to increased complexity, increased costs, protracted lead-times, low services and poor quality. The uncertainty circle model allows businesses to focus their change programs on particular areas of uncertainty. Uncertainty may be classified as;

- internal processes (say due to varying lead-times, machine breakdowns, absenteeism)

- supply side (such as poor supplier delivery performance, high parts per million reject scores)
- demand side (including schedule variability, short order book visibility)

- control (primarily production planning and control logic but may also include lack of adaptability of algorithm parameters)

The "uncertainty circle model" has been utilized to determine a "beaten path" [15] that companies follow in order to attain the vision of the seamless, integrated supply chain which does not suffer from the symptoms of high stock holding, poor customer service levels and excessive bullwhip. The stages of the beaten path are;

1. tighten internal process via the application of lean thinking

2. integrate suppliers via assessment and development

3. integrate with customers through collaborative working offering increased value-added services such as Vendor Managed Inventory (VMI) and Collaborative Planning, Forecasting and Replenishment (CPFR)

4. in parallel with the above three stages continuously re-engineer and/or improve the logistics control systems

\section{CONCLUSION}

The paper has demonstrated via a practical case study the application of system dynamics techniques in aiding decision-makers to define appropriate stock holding and ordering strategies. The techniques are particularly focused on reducing the impact of bullwhip in the supply chain.

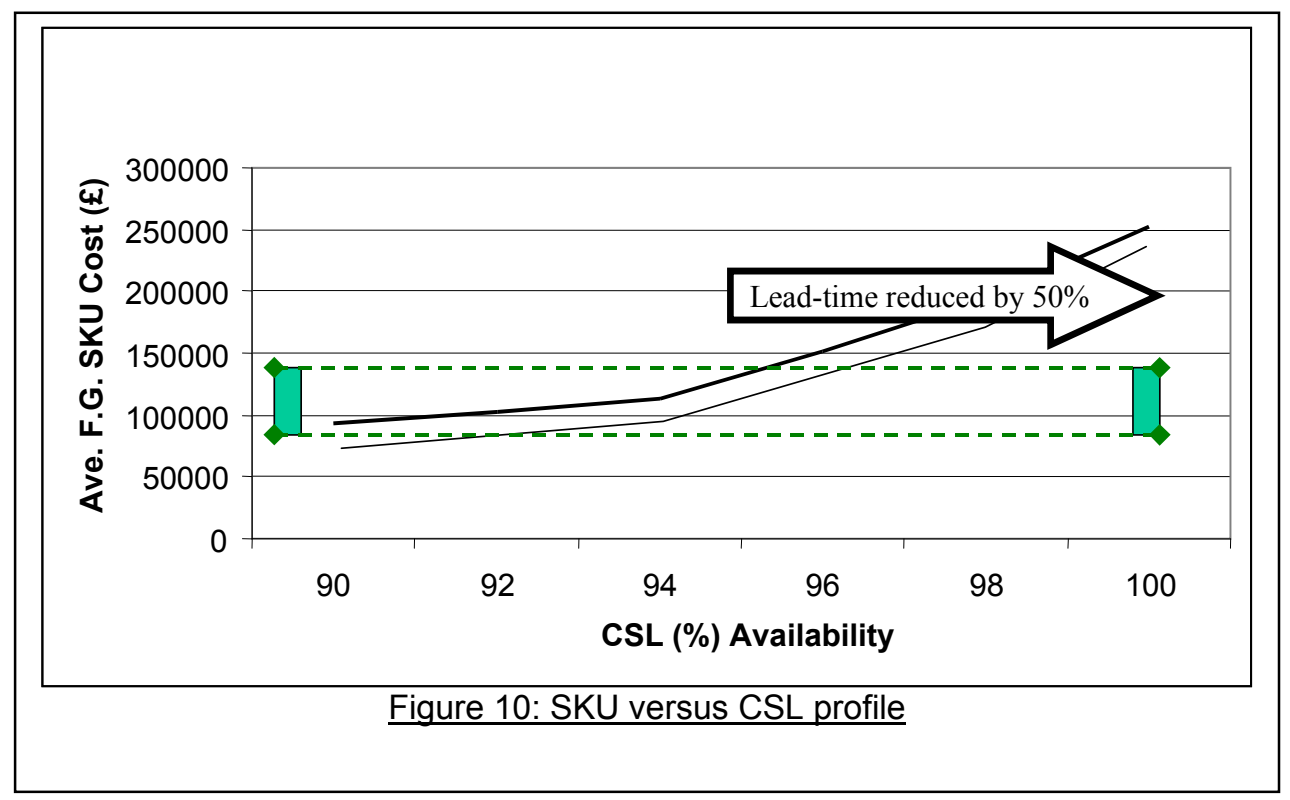

It has been shown that the decision support defines the "what" and the "how" of production planning and control. That is, what strategies are appropriate for which product categories and how the utilization of simulation modeling sets appropriate targets. Furthermore, the techniques highlighted aid strategic management in focusing resources where they will have maximum leverage in improving the performance of the supply chain.

\section{ACKNOWLEDGMENTS}

The authors would like to thank the sponsors of the research 

demonstrator", SAE 2002 Transactions Journal of Materials and Manufacturing, pp196-203. ISBN 0-7680-1289-9.

(EPSRC Innovative Manufacturing under the auspices of "Foresight Vehicle", TRW and CSC) and the numerous individuals who were involved in the research.

\section{REFERENCES}

1. Forrester, J.W., "Industrial dynamics", 1961, MIT Press, Cambridge, Mass

2. Burbidge, J. L., "Automated Production Control with a Simulation Capability", 1984, Proceedings of IFIP Conference WG5-7, Copenhagen, pp 1-14.

3. Lee, H.L., Padmanabhan, P. and Whang, S., "Information distortion in a supply chain: the bullwhip effect", Management Science, Vol. 43, 1997, pp543558.

4. Lee, H.L., Padmanabhan, V. and Whang, S., "The bullwhip effect in supply chains", Sloan Management Review, Spring 1997, pp93-102.

5. Davies, P., "Road Vehicles", EPSRC Commissioned Report, 1994

6. OST (Office of Science and Technology), "Technology Foresight - Manufacturing, Production and Business Processes", 1995, HMSO.

7. Berry, D., Evans, G.E., Mason-Jones, R. and Towill, D.R., "The BPR SCOPE paradigm in leveraging improved supply chain performance", Business Process Management Journal, Vol. 5, No.3, 1999, pp254-274.

8. Lewis, J., Naim, M., Wardle, S. and Williams, E., "Quick Scan your way to supply chain improvement", Institute of Operations Management, Control, 1998, Vol. 24, No. 5, pp 14-16.

9. http://www.cf.ac.uk/carbs/lom/lsdg/sc2001.html

10. Sterman, J.D., "Modeling managerial behavior; misperceptions of feedback in a dynamic decision making experiment”, 1989, Management Science, $35,3,321-339$.

11. Houlihan, J.B., "International supply chain management, International Journal of Physical Distribution and Materials Management, 1987, Vol. 17, No. 2, pp. 51-66.

12. Parnaby, J., "A systems approach to the implementation of JIT methodologies in Lucas Industries", 1988, Vol. 26, No. 3, pp 483-492.

13. Towill, D. R., "Dynamic analysis of an inventory and order based production control system", International Journal of Production Research, 1982, Vol. 20, No. 6, pp 671-687

14. Disney, S.M., Naim, M.M. and Towill, D.R., "Dynamic simulation modelling for lean logistics", International Journal of Physical Distribution and Logistics Management: Special Issue on Lean Logistics, 1997, Vol. 27, No. 3/4, pp 174-196.

15. Childerhouse, P., Disney, S.M., Towill, D.R., "The Uncertainty Circle as a Value Stream Audit Tool: A Case Study to Identify the BPR Requirements of the European Automotive Sector", Proc. of Eleventh Int.
Working Conf. on Production Economics, Igls, Austria, Vol. 3., Feb. 2000, pp119-130.

\section{CONTACT}

Dr M. M. Naim, Reader, Cardiff University, Chartered Engineer, Member of the Institution of Electrical Engineers (Manufacturing Division), Member of the Institute of Logistics and Transport, B.Eng (Tech), M.Sc. Ph.D.

e-mail: NaimMM@Cardiff.ac.uk

web: http://www.cf.ac.uk/carbs/lom/lsdg 
Naim, M.M., Disney, S.M. and Evans, G.N., (2002), "Minimum reasonable inventory and the bullwhip effect in an automotive enterprise; a "Foresight Vehicle" demonstrator", SAE 2002 Transactions Journal of Materials and Manufacturing, pp196-203. ISBN 0-7680-1289-9. 